\title{
Reflexiones en torno de la democracia y las elecciones ${ }^{1}$
}

Juan Huaylupo-Alcázar *

https://orcid.org/0000-0002-5183-4000

\section{Resumen}

Las reflexiones sobre las elecciones han constituido rupturas en contextos donde las dictaduras, militares y civiles, violentaron los derechos ciudadanos y la designación de gobernantes en la historia política latinoamericana. La participación social en procesos electorales contrastaba con las formas autocráticas ilegales e ilegítimas del poder estatal y rescataban derechos conculcados. El contraste de las elecciones con las dictaduras de facto contribuyó para considerar las elecciones con democracia, así Latinoamérica se hacía democrática con elecciones individualizadas; sin embargo, poco se ha analizado sobre la significación epistemológica, teórica e ideológica acerca de las elecciones o actos instrumentales y administrativos que captan y registran los votos, pero la democracia trasciende al voto y su magnitud, como tampoco es una expresión individualizada de la colectividad ni es la elección de quienes decidirán y actuarán en nombre de la ciudadanía. La democracia es la participación orgánica de la sociedad civil, del pensamiento y acción común de la heterogeneidad social. Las elecciones han validado dictadores, así como mediáticamente se confunde, distorsiona y condicionan votos con técnicas mercantiles. Pero, habría que anotar, que las elecciones también se convierten en un riesgo para tiranos; por ello, decepcionar electores con «todos son corruptos» para propiciar la abstención a los votantes, efectuar fraudes o pretender, con artimañas jurídicas, privatizar el poder político, se ha convertido en medios para controlar resultados y falsificar la democracia y lo público o lo común a todos. La situación y condiciones sociales imperantes en las sociedades constituyen el contexto que inciden en los procesos electorales y sus resultados.

Palabras clave: Autocracia, ciudadanía, legitimidad, poder.

* Estudios de doctorado en Comunicación y Paz en la Universidad para la Paz, de Costa Rica. Estudios de doctorado en Economía, con especialidad en Estado y Política Económica, en la Universidad Nacional Autónoma de México (UNAM), de México. Magister Scientiae en Ciencias Sociales, de la Facultad Latinoamericana de Ciencias Sociales (FLACSO), de México. Bachiller y Licenciado en Sociología. Universidad Nacional Mayor de San Marcos Facultad de Letras, de Perú. Autor de varios libros y decenas de artículos para revistas y libros. Catedrático en Administración Pública, Facultad de Ciencias Económicas de la Universidad de Costa Rica. Correo: huaylupoalcazar@gmail.com

\footnotetext{
${ }^{1}$ Aprobado por el comité editorial de la Revista Espiga en sesión del 14 de mayo de 2021. La sección en que se publica no es arbitrada mediante el proceso de pares.
} 


\section{Introducción}

Han sido miles de páginas y cientos de libros escritos en torno de la democracia y, posiblemente, sean infinitas las reflexiones particulares que se hacen sobre este fenómeno social, histórico y anhelo ciudadano, dado que no es posible agotar las conquistas singulares y particulares significaciones que tiene la democracia en cada ámbito social. La democracia es la expresión del dinamismo de realidades inéditas, que no son ni pueden ser semejantes a otras, así como tampoco son estáticas ni idénticas en cada espacio social ni tiene idéntica significación para los distintos grupos de interés, segmentos o clases sociales. Aspectos sobre los cuales existe un relativo consenso, no obstante, no es la forma general de comprenderla, ante las visiones estandarizadas predominantes.

La democracia es particular, sin embargo, la época, el contexto, la concepción occidental mecanicista de las cosas y realidades ha impuesto un criterio pragmático y estandarizado para comparar y valorar este proceso político de las sociedades, es el caso de hacerla equivalente a los procesos electorales, que es una forma reductiva y distorsionada de considerar la democracia, aspectos que serán analizados en el presente trabajo.

La democracia costarricense ha sido tipificada de modo diverso, pero en muchos casos ponderada positivamente y por estar sustentada en procesos electorales que no han conocido o evidenciado fraudes que pongan en duda sus resultados. Pero, la democracia es un proceso social dinámico, en relación con un contexto cambiante, no es equivalente a un proceso técnico ni cuantitativo, como las elecciones, aun cuando aceptadas, requieren su revisión y análisis porque se experimentan tiempos que degradan y liquidan la democracia, al implementarse acciones políticas contra lo público, el bienestar social y el desarrollo, no solo en el espacio nacional costarricense y centroamericano, sino también en Estados Unidos, Europa, incluso en Rusia y China, entre otros países del mundo. La democracia y las elecciones contemporáneamente son objeto de atención y preocupación política, social y académica. La celebración del bicentenario de la independencia y la constitución nacional como República, constituye el momento propicio para revisar las concepciones y prácticas electorales que se han valorado como democráticas.

\section{Democracia, una historia común}

Las referencias a la democracia y los enfrentamientos por alcanzarla cubren gran parte de la historia de los pueblos del mundo. Las luchas contra la desigualdad, la exclusión, la explotación y contra toda forma de esclavismo, sumisión y colonialidad del poder, ha sido la historia común de muchas colectividades del universo social. Se podría reescribir el pasado y el presente a través del recuerdo y recuento sobre las relaciones contradictorias entre democracia-dictadura en la constitución del poder en cada espacio social. Sin duda, no sería una historia de vencedores o dominadores, tampoco la visión individualista de caudillos, presidentes, militares, tiranos, caciques o gamonales, sería la historia de los subalternos, a quienes la historia oficial del poder les negó su protagonismo y cultura propia, así como se ha ocultado su participación en la construcción de la sociedad capitalista y la reproducción ampliada del capital y del Estado.

La democracia es la expresión orgánica de la heterogeneidad de las colectividades integradas e interdependientes, para decidir y actuar sobre aspectos que son comunes 
o públicos ${ }^{2}$. Sin embargo, esta noción generalmente no es conceptualizada ni reflexionada para referirse a la «democracia representativa», la cual distorsiona e individualiza la democracia que no se delega ni es individualizada, porque hace siempre referencia a una colectividad orgánica, activa y decisoria. El individualismo y la libertad en Occidente es una herencia griega que el capitalismo consolidó al ponderar la libertad individual como fundamento de su existencia, aun cuando solo se es libre entre personas libres ${ }^{3}$. La libertad griega en un universo de esclavitud era una paradoja, como lo es la libertad individual en un contexto global capitalista con explotación en subsunción real del trabajo y vida de los trabajadores.

La libertad y la democracia son determinaciones sociales que, en una sociedad inequitativa y contradictoria, no son procesos que sean perdurables en el tiempo ni en el espacio ${ }^{4}$, se conquistan y se conculcan en razón de la relación contradictoria entre los protagonistas sociales, así como de la actuación estatal, quien debería ampararlas y garantizarlas en cada contexto histórico particular.

La determinación colectiva del devenir, compartido y común, en la sociedad, es una aporía en el ejercicio de la arbitrariedad, unilateralidad y violencia del poder clasista y estatal contra las clases subalternas, como también lo es la desintegración orgánica, sin unidad cognoscitiva ni conciencia de los trabajadores, pero con capacidad de respuesta que auguran conflictos, antagonismos y enfrentamientos trágicos y dictaduras; esto, independientemente del signo ideológico, político o clasista, que serán preludios de nuevos luchas destructoras de bienestar y vidas. La derrota o el triunfo de la confrontación social o en los procesos electorales no son democracia ni la crean. El ascenso al poder con destrucción y muerte, no es democracia, como tampoco lo es la obtención de más votos electorales. Estas consideraciones limitan la construcción democrática contemporánea, quizás por vivir una transición de la democracia liberal, democracia burguesa, democracia representativa o del proceso que impide el reconocimiento, participación y beneficios de quienes, con su trabajo, sustentan el sistema capitalista y los privilegios privados imperantes, a la vez que inhiben la injerencia popular en las decisiones propias, sociales y de la nación ${ }^{5}$.

El pragmatismo individualista inherente de un sistema que ha privatizado el desarrollo y el bienestar social ${ }^{6}$, impide conocer la historia y el devenir de la sociedad, así como ha impuesto una concepción económica que privilegia el

\footnotetext{
${ }^{2}$ Giovanni Sartori, Teoría de la democracia (Buenos Aires: Editorial REI, 1990). Definir democracia en razón exclusiva de las experiencias concretas e históricas, conformaría un concepto caótico, impreciso e inclusive contradictorio. La adopción de alguna definición empírica concreta, descalifica otras concepciones y dogmatiza la escogida, lo cual elimina la visión prescriptiva sobre la democracia, que no son especulaciones ni la construcción de un tipo ideal, sino síntesis de concepciones y experiencias históricas, como también de las teorías existentes y sus evidencias, las cuales permiten aproximarse a la comprensión de procesos a los que cotidianamente se les denomina como democráticos (parlamentaria, representativa, estatal, burguesa, socialista, liberal, electoral, económica, industrial, etc.).

${ }^{3}$ René Zavaleta, «Cuatro conceptos de democracia», en La autodeterminación de las masas, comp. por Luis Tapia (Bogotá: Siglo del Hombre Editores (CLACSO), 2009).

${ }^{4}$ Osvaldo Iazzetta, «La democracia y los vaivenes de lo público-estatal», Revista Sociedad Argentina de Análisis Político (SAAP) 1, n. ${ }^{\circ} 2$ (2004): 377-407.

${ }^{5}$ Carlos Pereyra, Sobre la democracia en sociedades capitalistas y poscapitalistas (Jalisco: Instituto Electoral y de Participación Ciudadana del Estado de Jalisco. Serie Pensamiento Democrático en México, 2012). Lucio Colletti, «Estado de derecho y soberanía popular», en: Para una democracia socialista, de Colletti, Mylnár y Akademos (Barcelona: Cuadernos de Anagrama, 1976), 11-47. Giovanni Sartori, Teoría de la democracia (Buenos Aires: Editorial REI, 1990).

${ }^{6}$ Atilio Borón y Kirk Mann, La privatización del bienestar (San José: Secretaria General de la Facultad Latinoamericana de Ciencias Sociales / FLACSO, 1992).
} 
crecimiento y la concentración económica privada, como determinante del pasado y presente, a la vez que subordina el conocimiento científico.

\section{Organicidad social y democracia}

El capitalismo es la forma económica que posibilitó la organicidad productiva de la fuerza de trabajo y también permitió crear valores nuevos sin, necesariamente, invadir para apropiarse de la riqueza de otros espacios sociales. Se creaba un sistema interdependiente entre el campo y la ciudad, entre las diversas y crecientes formas de distribución de trabajos especializados con actores sociales y sociedades más allá de los contextos nacionales. Esto es, se había creado un sistema que requería el incesante y creciente complemento de cada vez más poblaciones y pueblos del mundo, además exigía el establecimiento de relaciones políticas, cognoscitivas, culturales e ideológicas, como articulación necesaria para la expansión e intensificación de relaciones de una nueva época. Las revoluciones americana y francesa fueron los actos sociales que inauguraron políticamente el capitalismo, la ciudadanía y lo público. La igualdad y la libertad fueron los momentos constitutivos para un sistema económico que tenía la potencialidad de crecer en reproducción ampliada, eliminando o relativizando sus obstáculos para su expansión y crecimiento. El espíritu de la época exigía de una nueva forma política para regular las relaciones sociales; así, la democracia que, si bien no fue creada por el capital, sino que surge como resultado del fin de las relaciones de una sola clase social sobre las otras, pero sirvió para que la burguesía envileciera el espíritu libertario original que inspiró la transformación, además modeló un Estado que garantizara las nuevas relaciones sociales entre las clases, pero conservando el mismo espíritu autocrático de aquellos que fueron defenestrados ${ }^{7}$. La crisis del sistema, previo al capitalista, no fue predominantemente económica, sino política, tampoco, la creación capitalista fue una creación predominante ni exclusivamente económica.

La organicidad de la gran producción capitalista era también la organicidad de los distintos actores sociales para establecer interacciones libres, necesarias e igualitarias en las negociaciones y los acuerdos mancomunados, como condición para crecer y expandir las relaciones sociales en el espacio nacional e internacional ${ }^{8}$.

La sociedad capitalista ha requerido de la libertad como una necesidad y condición para la integración y el complemento entre sociedades, culturas y la construcción de una historia común, por ello también es un requisito para la inversión, la rentabilidad y la expansión del capital; esto es, el capitalismo no fue un logro de la clase burguesa, sino de todas las clases y del Estado, en las condiciones imperantes de cada contexto social particular. La democracia no es un acto mecánico ni instrumental, es la decisión y acción de la colectividad libre de toda subordinación para la convivencia, relaciones igualitarias y el bien común en un espacio social compartido. Es una práctica individual, en tanto que perteneciente a una colectividad identitaria.

La apropiación privada de lo generado colectivamente, sin reconocimiento ni distribución social de la riqueza, es un atentado contra la democracia y el equilibrio

\footnotetext{
${ }^{7}$ Sebastián Salazar, La alternativa del burgués. Escritos políticos y morales (Perú: 1954-1965) (Lima: Clásicos Sanmarquinos, Fondo Editorial de la Universidad Nacional Mayor de San Marcos, 2003), 155-156.

${ }^{8}$ Ferdinad Braudel, La dinámica del capitalismo (México: Fondo de Cultura Económica, 2002). Juan Huaylupo, «Economía, sociedad y ambiente», Revista Ciencias Económicas 25, n. 1 (2008): 109126.
} 
sistémico, así como contra los otros protagonistas y sociedades que hicieron posible el capitalismo.

Desconocer y no reconocer cognoscitiva e ideológicamente que la socialidad productiva, en democracia, se encuentra determinada comunitaria y estatalmente, en tanto que pública y nacional, niega su constitución originaria y devenir cotidiano, así como descalifica su pertinencia y consistencia. La reproducción sistémica del capitalismo, de ningún modo, es un atributo privado de autócratas ni de los propietarios del capital ${ }^{9}$. El poder del pueblo o democracia es aún una ilusión que no ha sido posible ejercer, mientras ello ocurra, el poder formal será de los electos o los golpistas de Estado, mientras el poder real es de la clase propietaria del capital. La opción totalitaria del individualismo posesivo en la economía y sociedad no es ni será pública ni nacional ${ }^{10}$.

No obstante, estas condiciones fundacionales del capitalismo han cambiado con los tiempos, con la consolidación concentrada y centralizada del capital y del poder político-militar mundial, que se han impuesto a las culturas, a la soberanía de los pueblos y derechos ciudadanos, así como se ha formalizado y legitimado jurídica, mediática e ideológicamente.

La negación de la libertad, la igualdad formal o la renuncia a la democracia de algún actor social, la exclusión de otras clases o la discriminación a su representación orgánica, es la negación de la democracia, para ser una regresión totalitaria. La democracia es una necesidad, no es un artificio colateral ni sustituible, ella requiere comunidad, identidad y acción colectiva.

La productividad y rentabilidad del trabajo capitalista no es individual, es colectiva, ni las preocupaciones, promociones e incentivos por el crecimiento económico es una opción para el bienestar ciudadano, como tampoco lo es para el progreso de las sociedades. El desarrollo y el bien común implican la existencia de democracia, pero el esfuerzo colectivo para el beneficio privado, es dictadura. La pretensión del privilegio empresarial privado en la pandemia contemporánea es la absurda reedición del economicismo, es la regresión cognoscitiva y política para las sociedades.

La difundida creencia de que la democracia es la acción estatal para complacer a las demandas y anhelos de los grupos y clases sociales, a pesar de sus heterogeneidades, contradicciones y de aspiraciones, es inconsistente y antagónica. La acción estatal tiene como función esencial, garantizar la reproducción, defensa y amparo de la función pública y la democracia. La democracia no niega los intereses privados, puesto que están comprendidos en lo público, en lo común a todos, razón por la cual la política pública es un requisito de la actuación estatal, porque nadie es autónomo ni logra sus propósitos de modo aislado de otros individuos, los grupos y clases sociales sin afectar a los otros. El haber abusado, denigrado y empobrecido a muchos para beneficiar a pocos, es una transgresión a lo público y la democracia. La reproducción democrática, supone el compromiso y participación de la pluralidad social, no es un asunto técnico, burocrático, virtual ni pertenece al Estado, es de la ciudadanía activa y comprometida con el bien común. La sustitución de la política

\footnotetext{
${ }^{9}$ Immanuel Wallerstein, Universalismo europeo (México: Siglo Veintiuno Editores, 2007).

${ }^{10}$ Crawford Macpherson, La teoría política del individualismo posesivo de Hobbes a Locke (Madrid: Editorial Trotta, 2005).
} 
pública por prácticas burocráticas y gerenciales en el quehacer estatal es la privatización de la política.

La democracia como proceso inédito y peculiar de cada colectividad, es en la actualidad recurrentemente falsificada con aplicaciones técnicas e instrumentos que ignoran, niegan o son indiferentes de la historia, voluntad y acción de las sociedades. Así, respetar los resultados electorales con independencia de su legalidad y legitimidad social, así como de la inmunidad e impunidad ante la transgresión de lo público y lo nacional, viola y liquida la democracia.

La comparación de procesos políticos entre países, a través de variables e indicadores estandarizados, sin teoría explicita y sin tomar en cuenta las particularidades políticas de cada espacio social, ha sido el medio usado generalmente para medir, clasificar y descalificar sociedades. Esto es, se asume erradamente que los procesos políticos y particularmente la democracia, se representan empíricamente de modo idéntico y que poseen igual significación independientemente de las sociedades.

La concepción epistemológica positivista, específicamente empirista, cree que la democracia es única, idéntica y universal, así como se establece, valorativa y arbitrariamente, que alguna sociedad es un modelo a ser emulado, independientemente de las formas culturales y nacionales, de las formas de vida, historia y voluntad de los pueblos. Así, lo particular e inédito ha sido negado y despreciado, para imponer estadísticamente el patrón de la sociedad dominante que excluye la existencia de la diversidad de las formas democráticas en el mundo.

Asimismo, debe anotarse que la universalidad del voto es valorado y difundido como una gran conquista democrática $\mathrm{y}$, como tal, se ha plasmado como fundamento para la delegación individual al poder del Estado y en otros casos, la votación, aun cuando restrictiva, constituyen medios para otorgar facultades decisorias a personas del aparato institucional estatal. De este modo, legal, partidaria y mediáticamente, se califica como democracia al simple hecho de concurrir a las urnas electorales para depositar el voto, se podría afirmar que la votación se ha convertido en una forma de convertir a las colectividades sociales en agregados de individuos aislados que, sin concertación ni comunidad de ideas, otorgan poderes a otros individuos, que se transforman en autócratas y en muchos casos sin las facultades necesarias ni especializadas para el cumplimiento de funciones públicas. Las mayorías electorales, «solo agregados efímeros» ${ }^{11}$, sin significación ni contenido, luego las mayorías no constituyen dictaduras ni democracias. En la democracia representativa, los electos no representan a sus electores que desconocen, tampoco puede representar lo público, que no están obligados a conocer $\mathrm{y}$, menos aún, podrá representar lo nacional, como tampoco tienen posición sobre las relaciones del país en el concierto internacional, lo cual regularmente es una problemática compleja, dinámica y que excede las capacidades individuales. Pero, la propia ciudadanía carece de la experiencia, conocimientos y opinión sobre el acontecer y problemática del país, luego no tiene capacidad crítica sobre las opiniones y posiciones de los candidatos por elegir. Esto es, el proceso electoral no decide sobre las cuestiones que afligen a la colectividad, solo decide a quién decidirá sobre las cuestiones que considera necesarias, aunque no necesariamente serán públicas ni nacionales. Ante este

\footnotetext{
${ }^{11}$ Giovanni Sartori, La democracia en 30 lecciones (Buenos Aires: Editorial Taurus, 2009), 46.
} 
panorama, el proceso electoral garantiza la conservación y continuidad de las condiciones impuestas por el poder.

La decepción política de la ciudadanía a los procesos electorales se manifiesta de diversas maneras, el voto nulo, en blanco o el abstencionismo, pero adquieren importancia para el poder imperante, por ello la manipulación corrupta de las personas y sus votos, así como el chantaje, el uso extendido e intensivo de falsedades y la difamación mediática o el uso tecnológico fraudulento en el conteo de votos. Las elecciones solo son formas aparentes de democracia.

\section{Democracia, elecciones y capitalismo}

Las elecciones como una práctica para elegir autoridades en los espacios sociales distintos y heterogéneos, se instauraron en periodos y circunstancias diferentes, siendo producto, en muchos casos, de luchas y conquistas de los pueblos, así como de la adopción de regulaciones políticas particulares, según situación, condiciones, preocupaciones o creencias para resolver y actuar sobre asuntos colectivos, lejos de determinaciones autocráticas o totalitarias. Las elecciones constituyeron una expresión colectiva para arrebatar del poder a quien disponía del quehacer, trabajo y futuro de muchos. Esto es, fue el medio aceptado socialmente para erradicar las distintas formas opresivas de dominación, en espacios sociales donde se creaban conciencia, organicidad y voluntad para transformar y socializar la designación del poder formal. Las elecciones ilusoriamente abrían nuevas rutas en el devenir político de los pueblos y sociedades, así como inauguraba la participación política a las poblaciones que nunca antes fueron consultadas ni tenían derechos para definir un destino común. Sin embargo, en ese proceso las necesidades colectivas de pueblos, trabajadores, excluidos o explotados, han sido sustituidas por acciones particulares aisladas, sin considerar opciones ni actuación que resuelva problemáticas derivadas del ejercicio inequitativo del poder, que empobrecen y profundizan la polaridad y el malestar social. Los procesos electorales crearon ilusiones utópicas para la transformación pacífica, pero han servido para dar continuidad y reproducir el statu quo. Así, en una sociedad inequitativa, clasista y contradictoria, las elecciones no son consensuales y la efímera mayoría no tendrá la fuerza, voluntad ni conciencia para la transformación de la sociedad.

Las elecciones es un constructo social e histórico, creado a lo largo de los tiempos en todas las formas complejas de organicidad social, aun cuando no siempre exitosas ni triunfantes, porque los contendientes responden a intereses y creencias distintas en la heterogeneidad sistémica de la sociedad. Los procesos electorales están insertos en un contexto estructural que les impone patrones que regulan su actuación, en parte por su origen religioso feudal, fueron los monjes quienes crearon las elecciones, optando por elegir con votación secreta a sus superiores, dada la imposibilidad de nominación por herencia o mediante la fuerza ${ }^{12}$. Así, se otorgaba un poder absoluto al electo, no para transformar radicalmente la iglesia, sino para conservarla, reproducirla y extenderla, en un patrón que aún se reproduce en distintas religiones ${ }^{13}$.

\footnotetext{
12 Ibíd.

${ }^{13}$ Tomas Várnagy, «El pensamiento político de John Locke y el surgimiento del liberalismo», en La filosofia política moderna. De Hobbes a Marx, comp. por Atilio Boron (Buenos Aires: Consejo Latinoamericano de Ciencias Sociales / CLACSO, 2000), 41-76. La liberación de la política de la teología, en el siglo XVII, modificaba la elección por unanimidad a la elección por mayoría por la influencia de John Locke. Esto es, no se aceptaba la discrepancia, la unanimidad encubría el disenso, si bien la vigencia de la mayoría supera esa visión y práctica, aun en el presente se condiciona,
} 
En el presente capitalista, las elecciones no revolucionan la economía ni el poder, incluso cuando los electos son críticos del sistema o socialistas.

La magnificación de las elecciones en la actualidad es extraordinaria e incluso son consideradas como determinantes en la constitución de la democracia en los pueblos, al extremo de afirmar que no existe democracia sin elecciones. La equivalencia de la democracia con elecciones la transfigura para dogmatizar y fetichizar lo técnico y administrativo, siendo la democracia un proceso que compromete y redefine el poder y la sociedad.

La creencia de que las elecciones poseen igual significación para las sociedades y de que en todos los contextos constituyen la democracia, es desconocer la diversidad de condiciones sociales y políticas que han creado múltiples formas electorales que han surgido y existen en las sociedades. Asimismo, suponer que la democracia está circunscrita a las elecciones, es ignorar los distintos modos de expresar la voluntad ciudadana, que son dependientes de cada cultura, historia y circunstancias estructurales y coyunturales, donde se gestan y realizan los procesos democráticos. Las elecciones o la cosificación de la democracia, es una reducción y regresión cognoscitiva, que impide comprender la complejidad social.

Las elecciones poseen significaciones particulares, no pueden ser comparadas por obedecer a circunstancias específicas ¿Por qué se vota? ¿En qué condiciones se efectúan las elecciones? ¿Cuáles son las pautas electorales? ¿Quiénes votan? ¿Tienen los votos igual valor? ¿Pueden votar todos? ¿Son los votos libres de condicionamientos? Estas son algunas preguntas, entre otras, que pueden formularse. Los procesos electorales son heterogéneos, las personas con derecho al voto también varían, las mujeres, las personas de color, la edad, estado civil, presos, asilados, etc., son distintos y son modificados incesantemente, luego no es posible suponer los procesos electorales como expresión de la democracia en los contextos donde se realizan, dado que están determinados política, jurídica e ideológicamente desde el poder prevaleciente.

Las elecciones constituyeron, en la historia latinoamericana, un significativo avance en los procesos políticos, fueron el medio para que las poblaciones participaran en la designación de la autoridad en la conducción gubernamental y constituyeron rupturas ante gobiernos de facto, representantes de intereses dominantes de la colonialidad del poder. En la conquista ciudadana por la construcción democrática, las elecciones fueron una esperanza; sin embargo, hoy se reconoce, por conocimientos epistemológicos, teóricos y de experiencias concretas, que la democracia no es equivalente a elecciones, ni garantizan democracia. Así, el sufragio universal, expresión máxima del proceso electoral, no es una democracia directa ni participativa, ese voto, «no es para decidir, sino para elegir a quien deberá decidir» ${ }^{14}$. Esto es, la democracia debe representar y gobernar para todos. Un ejercicio gubernamental privativo es una transgresión a los implícitos de la democracia y del propio proceso electoral, como también lo es, el uso de las votaciones para validar tiranías.

\footnotetext{
soborna y coacta el voto para obtener unanimidades o mayorías, como ocurre con la elección de magistrados del Poder Judicial en Costa Rica (Solís, 2018), la persistencia del voto cautivo, la mercantilización mediática, el financiamiento estatal preferencial a partidos políticos, o la intromisión financiera privada que media la acción estatal a los partidos en contienda electoral.

${ }^{14}$ Norberto Bobbio, Teoría general de la política (España: Editorial Trotta, 2009), 402.
} 
Los procesos electorales están conformados por procesos técnicos y procedimientos administrativos (votación por correo, obligatorias, voluntarias, directa o delegativa, conteo manual o electrónico, etc.), que tienen implícitos sociales y políticos, no siempre explicitados, pero determinados por procesos políticos, jurídicos, administrativos y técnicos ${ }^{15}$. Esto es, los procesos electorales no son inmutables ni independientes de sus modalidades, del contexto ${ }^{16}$, del ejercicio del poder ni las valoraciones, participación y comunicación entre los electores ${ }^{17}$.

En tal sentido, suponer que las elecciones poseen características y propósitos iguales o similares, es ignorar la complejidad de procesos implicados en la constitución de los sistemas electorales ${ }^{18}$, como hace incomprensible la concepción de democracia, así como vacía de contenido la noción de elecciones. Ningún procedimiento de naturaleza instrumental, tiene validez universal, menos aún en consideraciones de naturaleza social, histórica y cultural ${ }^{19}$.

Cuando se analiza la democracia en América Latina, es relativamente frecuente caracterizarla en crisis; pero, paradójicamente, no son interpretadas como resultado de los procesos electorales ${ }^{20}$, tampoco por las plataformas propagandísticas de los partidos políticos ni por los candidatos de la contienda electoral, así como es obvio que el acto técnico e instrumental de votar no supedita procesos sociales y políticos. No obstante, el Tribunal Supremo de Elecciones de Costa Rica se arroga ser el «pilar de la democracia» en el país, cuando sus actividades se limitan a procedimientos burocráticos, así como en la aplicación de técnicas e instrumentos sin relación alguna con la democracia ${ }^{21}$.

El acto electoral no es ni crea democracia. La individualización del voto reduce y fetichiza las relaciones sociales y organicidad social de la democracia. La elección del individuo que conducirá un gobierno en una sociedad interdependiente, polarizada y contradictoria, es la reedición política del dominio autocrático. La elección de ningún modo lo faculta a ejercer un poder privativo, como tampoco implica ignorar la pluralidad social, por el contrario, el gobierno tiene una determinación dependiente de la sociedad que gobierna. La democracia no es de individuos para individuos, es para todos en la pluralidad y heterogeneidad social. La sociedad no es un conglomerado amorfo, es una unidad integrada e interdependiente, aun cuando desigual y contradictoria.

En la actualidad en ocasión del bicentenario de la independencia, revisar las concepciones y consistencia de los procesos electorales como requisito para la libertad y democracia es una necesidad, dado que en el presente se experimentan tiempos donde las dictaduras se afirman como democracias con solo efectuar elecciones, o cuando tiranos modifican constituciones y leyes para legalizar formas

\footnotetext{
15 Jorge Urdánoz, «Un nuevo marco conceptual para el análisis electoral», Logroño, España (tesis doctoral, Universidad de La Rioja, 2005).

${ }^{16}$ Edel Cadena y Juan Campos, «Vulnerabilidad social y comportamiento electoral. Un análisis por secciones electorales», Revista Papeles de Población, n..$^{\circ}$ 71, (2012): 1-43.

${ }^{17}$ Ergon Montecinos, «Análisis del comportamiento electoral: De la elección racional a la teoría de redes», Revista de Ciencias Sociales 13, n. ${ }^{\circ} 1$ (2007): 9-22.

${ }^{18}$ Fernando Tuesta, «Sistemas electorales en América Latina», Revista Instituto Interamericano de Derechos Humanos, n. $^{\circ} 42$ (2005): 145-160.

${ }^{19}$ Max Horkheimer, Crítica a la razón instrumental (Buenos Aires: Editorial Sur, 1973).

${ }^{20}$ Edelberto Torres, «Las crisis de las democracias en América Latina», Revista Instituto Interamericano de Derechos Humanos, n. $^{\circ} 42$ (2005): 211-225.

${ }^{21}$ Juan Huaylupo, «¿Dónde está el Tribunal Supremo de Elecciones?», Elpaís.cr, San José, 28 de marzo 2018, https://www.elpais.cr/2018/03/23/donde-esta-el-tribunal-supremo-de-elecciones/
} 
totalitarias, como ocurrió con Pinochet en Chile, Fujimori en el Perú, o Añez en Bolivia. Asimismo, argumenta una crisis financiera estatal para amparar privilegiadamente a empresarios y financistas globales, empobreciendo sectores medios y pobres, como ocurre en el contexto nacional costarricense. En la historia latinoamericana elegir a autócratas ha sido una historia común.

La democracia requiere de relaciones igualitarias de un tipo particular de sociedad que el mecanismo electoral no garantiza, el cual no es compatible con una economía de mercado donde las relaciones se sustentan en la reproducción incesante de la desigualdad. La supeditación de la democracia a la desigualdad de las relaciones económicas es su conversión en un sistema de gobierno subordinado y al servicio del capitalismo, que niega la igualdad, la libertad y la democracia para las masas, a las cuales considera ineptas, ignorantes e incapaces de conducir una sociedad ${ }^{22}$, por ello sus representantes no son reconocidos ni cuando triunfan electoralmente.

En contextos ilegales e ilegítimos de América, las elecciones fueron apreciadas como triunfos de la democracia, aun cuando en algunos casos encubrían y validaban tiranos. No obstante, las protestas y movimientos sociales que han defenestrado dictaduras son calificadas como luchas democráticas o, contrariamente, cuando triunfa políticamente algún representante popular con elecciones, algunos sectores sociales y acciones nacionales e internacionales, las desconocen y buscan anularlas. Por sí mismas, ni las elecciones ni las protestas sociales constituyen signos que puedan caracterizarlas como democráticas.

Las mal llamadas «democracias del voto» no son manifestaciones democráticas de la colectividad nacional, pues ni la designación de los candidatos ni los programas de gobierno son el producto de consulta ciudadana, de debate partidario ni nacional, solo son agregados de votos individualizados que carecen de significación que sea común, más allá del acto mecánico cuantitativo. Los votos solo interesan en tanto que conforman magnitudes para ganar una elección, no representan la heterogeneidad de los intereses y anhelos de una colectividad desigual, contradictoria y orgánicamente desintegrada en razón de lo común y lo nacional.

La opción individualizada del voto para designar a quienes representarán la ciudadanía, es el otorgamiento de una facultad, jurídica e institucional, a un individuo que no tiene obligación alguna para una actuación común a todos o, dicho de otro modo, es la concesión formal de un individuo para decidir y actuar sobre la colectividad y nación, por haber triunfado en una contienda electoral.

Gobernar autocráticamente o para el beneficio de algún sector exclusivo de la sociedad transgrede la democracia; sin embargo, no es motivo de preocupación u objeto de intervención de ningún tribunal electoral, en correspondencia con su rol burocrático, parcializado y cómplice con las estructuras de poder prevalecientes. Elecciones para la conservación del statu quo o cambiar para que todo siga igual, son al parecer historias comunes en muchos de los espacios nacionales. La libertad y democracia en la economía de mercado es la de los propietarios del capital, es privada.

En democracia, los gobiernos son interdependientes con la totalidad social, se puede afirmar incluso que deben ser dependientes de la situación, decisión y actuación de cada sociedad civil. Una lectura y actuación parcial y parcializada del gobierno en

${ }^{22}$ Colletti, «Estado de derecho... 
la sociedad o que pretenda autonomizarse; sin duda, no será un gobierno democrático, será autocracia. La democracia del capital, no es democracia de todos para todos.

Teñir de democracia las dictaduras, por haber sido electas por una mayoría, es un absurdo. Ningún triunfo electoral supone una «carta en blanco» para que los gobiernos enmascaren $u$ oculten decisiones y acciones contra todos a quienes no representa. Ninguna elección puede calificar y justificar como democracia la imposición tiránica de unos contra los otros. La mayoría electoral no supone la totalidad social ni nacional, como tampoco implica la pérdida de los derechos humanos y ciudadanos.

El propósito del proceso electoral es la obtención de un resultado cuantitativo que determine un ganador, aun cuando los votos son producto de decisiones individuales distintas e inclusive contradictorias. Los votos obtenidos por los candidatos homogenizan cuantitativamente su heterogeneidad cualitativa. La mayoría solo es una cantidad, sin homogeneidad ni significación política. El desconocimiento de la significación de la diversidad de criterios, conocimientos y valoraciones que sustenta cada voto, no interesan en los procesos electorales, solo importa la magnitud de los votos, a pesar de que la ponderación de la individualidad del voto es negada e ignora la subjetividad, conocimientos y anhelos ciudadanos para solo contar, exclusivamente, la cantidad de votos.

La disociación de la cantidad con la cualidad, invierte y contamina la racionalidad de la decisión de la participación ciudadana, por ello se manipula mediática, técnica, demagógica o corruptamente la búsqueda por obtener votos. Asimismo, los procesos electorales magnifican los procedimientos e instrumentos, cosifican y falsifican la concepción de la democracia para convertirse en un modo de usurpar la voluntad política ciudadana.

La individualización del proceso electoral otorga a los candidatos el monopolio de la ponderación sobre la problemática social y sus soluciones que, sin participación ni debate ciudadano, asumen una posición omnisapiente y omnipotente sobre el pensamiento y voz de la colectividad que solo debe votar. De modo similar, el gobernante electo, se arroga la potestad de convertirse en un autócrata que conserva o redefine la actuación institucional, la distribución social de los recursos del Estado y de los excedentes generados socialmente.

De este modo, creer que las elecciones garantizarán los intereses comunes de los distintos protagonistas sociales y de la nación, es una ilusión por las circunstancias que lo pautan, por el control parcializado del poder gubernamental, por intereses particulares de los electores, por las visiones que han fetichizado el crecimiento económico como el fundamento para el desarrollo y el bienestar, y porque las organizaciones políticas y los candidatos enarbolan en sus plataformas electorales un discurso clientelista, demagógico y contradictorio, que son olvidados pues, el discurso electoral es para obtener de votos, no son compromisos por cumplir en el poder.

Lo común, democrático, lo nacional y la actuación colectiva no forma parte del debate electoral mediático, como tampoco es valorado trascendente por los tribunales electorales, los partidos políticos ni los electores, dado que esperan una práctica que los beneficie directamente.

De este modo, ni los procesos electorales, administrativos ni legales, garantizan transformaciones drásticas de las sociedades, como tampoco provocan angustia ni 
terror a los poderes ni a los privilegiados del sistema, porque ningún poder ni partido político hace caso omiso, a la seguridad ni al derecho ${ }^{23}$. Esto es, el monopolio de la coacción, no solo está referido exclusivamente al uso de la fuerza, dado que el derecho es una garantía para la conservación de las condiciones existentes o el orden establecido, y porque es la formalización de una ideología generadora y reproductora del miedo contra todas las formas que pretendan cambios estructurales y sociales radicales.

La supuesta democracia representativa, no representa a quienes le otorgaron el voto, tampoco puede representar lo público que no están obligados a conocer $\mathrm{y}$, menos aún, podrá representar lo nacional, lo cual regularmente es una problemática compleja, dinámica y que excede las capacidades individuales. El proceso electoral no decide sobre las cuestiones que afligen a la colectividad, solo decide a quién decidirá sobre las cuestiones públicas y nacionales. De este modo, se garantiza la conservación y continuidad del poder.

La decepción política de la ciudadanía hacia los procesos electorales se manifiesta de diversas maneras, como el voto nulo, en blanco o el abstencionismo, pero las elecciones adquieren mayor importancia para el poder imperante; por ello, la corrupción de las personas y la manipulación de los votos, así como el chantaje, el uso extendido e intensivo de falsedades y la difamación mediática o el uso tecnológico fraudulento en el conteo de votos. Las elecciones solo son formas aparentes de democracia.

Los procesos electorales no son hechuras del capitalismo, pero le son útiles y necesarias para reproducirse y validarse en la sociedad. El Estado pondera las elecciones por ser un medio para perpetuar el poder excluyente, para amparar a propietarios que se creen dueños de la nación, protegidos jurídica y mediáticamente, a la vez que desprecian la democracia en su nombre, como también lo hacía Hitler $^{24}$. Las elecciones son actos administrativos e instrumentales del poder para el poder, muy lejano de toda influencia ciudadana. El prejuicio absurdo que aprecia los valores y patrones de vida de la colonialidad del poder es una forma excluyente que desprecia lo propio, como modo de dominación, nunca como democracia.

La imposición de la ideología necesaria del capitalismo, del individualismo posesivo y el liberalismo electoral, limita la identidad y unidad de los subalternos, a la vez que les impide ser actores de su propio desarrollo, de la valoración de su contribución en la economía y de la reproducción del sistema. La invocación estatal al desarrollo desde la perspectiva privada y empresarial es ajena a los subalternos, empobrecedora y déspota contra la población trabajadores y pobres de las naciones.

\footnotetext{
${ }^{23}$ Max Weber, Economía y Sociedad (México: Fondo de Cultura Económica, 1969), 26-28. Eduardo Novoa, El derecho como obstáculo al cambio social, México: Siglo XXI Editores, 1975. Hans Kelsen, Teoría General del Derecho y el Estado (México: Universidad Nacional Autónoma de México, 1988.

${ }^{24}$ Carta de Adolfo Hitler dirigida a Adolfo Gemlich en 1919, encontrada en los archivos nazis cerca de Nuremberg en 1945, en la cual menciona «la eliminación de los judíos» (Entfermung der Juden) y el antisemitismo. Misiva conocida como «Carta a Geimlich» (https://cnnespanol.cnn.com/2011/06/08/hitler-ya-hablaba-de-exterminar-a-los-judios-en-una-cartade-1919/). El discurso sobre la democracia de Hitler, se efectuó ante los trabajadores de armamento el 10 de diciembre de 1940 en Berlín, en el cual hace una aguda crítica a la democracia representativa de Occidente, comparándose parcializadamente en un contexto que contribuyó a fundar uno de los más sanguinarios regímenes totalitarios que ha conocido la humanidad (https://www.ersilias.com/discursos-de-adolf-hitler/).
} 
La exclusión de la población en los asuntos sobre su situación, condición y sobre lo público, ha originado que América Latina sea la región de la mayor polaridad social del mundo, le convierte en un espacio con un extendido proceso de corrupción, que no exime a Costa Rica, la cual se encuentra en crisis democrática, en la que la ciudadanía carece de una capacidad fiscalizadora sobre función pública y del Estado.

\section{Formato de citación según APA}

Huaylupo-Alcázar, J. (2021). Reflexiones en torno de la democracia y las elecciones. Revista Espiga, 20 (42), 65-79.

Formato de citación según Chicago-Deusto

Huaylupo-Alcázar, Juan. «Reflexiones en torno de la democracia y las elecciones». Revista Espiga 20, n. ${ }^{\circ} 42$ (setiembre, 2021): 65-79. 


\section{Referencias}

Bobbio, Norberto. Teoría general de la política. España: Editorial Trotta, 2009.

Bovero, Michelangelo. «¿Elecciones sin democracia? ¿Democracia sin elecciones? Sobre las formas de participación política». Acervo de la Biblioteca Jurídica Virtual del instituto Jurídico de la UNAM (2012), 317-350. www.bibliojuridica.org

Borón, Atilio y Mann, Kirk. La privatización del bienestar. San José: Secretaría General de la Facultad Latinoamericana de Ciencias Sociales (FLACSO), 1992.

Braudel, Ferdinad. La dinámica del capitalismo. Ciudad de México: Fondo de Cultura Económica, 2002.

Cadena, Edel y Campos, Juan. «Vulnerabilidad social y comportamiento electoral. Un análisis por secciones electorales». Revista Papeles de Población, n. ${ }^{\circ} 71$ (2012): 1-43.

Colletti, Lucio. «Estado de derecho y soberanía popular». En: Para una democracia socialista de Colletti, Mylnár y Akademos, 11-47. Barcelona: Cuadernos de Anagrama, 1976.

Horkheimer, Max. Crítica a la razón instrumental. Buenos Aires: Editorial Sur, 1973.

Huaylupo, Juan. «Economía, sociedad y ambiente». Revista Ciencias Económicas 25, n. ${ }^{\circ} 1$ (2008): 109-126.

Huaylupo, Juan. «¿Dónde está el Tribunal Supremo de Elecciones?». Elpaís.cr, 28 de marzo, 2018. https://www.elpais.cr/2018/03/23/donde-esta-el-tribunalsupremo-de-elecciones/

Iazzetta, Osvaldo. «La democracia y los vaivenes de lo público-estatal». Revista Sociedad Argentina de Análisis Político (SAAP) 1, n. ${ }^{\circ} 2$ (2003): 377-407.

Kelsen, Hans. Teoría General del Derecho y el Estado. Ciudad de México: Universidad Nacional Autónoma de México, 1988.

Macpherson, Crawford. La teoría politica del individualismo posesivo de Hobbes a Locke. Madrid: Editorial Trotta, 2005.

Montecinos, Egon. «Análisis del comportamiento electoral: De la elección racional a la teoría de redes». Revista de Ciencias Sociales 13, n. 1 (2007): 9-22.

Novoa, Eduardo. El derecho como obstáculo al cambio social. Ciudad de México: Siglo XXI Editores, 1975. 
Pereyra, Carlos. Sobre la democracia. Jalisco: Instituto Electoral y de Participación Ciudadana del Estado de Jalisco. Serie Pensamiento Democrático en México, 2012.

Salazar, Sebastián. Escritos políticos y morales (Perú: 1954-1965). Lima: Clásicos Sanmarquinos. Fondo Editorial de la Universidad Nacional Mayor de San Marcos, 2003.

Sartori, Giovanni. Teoría de la democracia. Buenos Aires: Editorial REI, 1990.

Sartori, Giovanni. La democracia en 30 lecciones. Buenos Aires. Editorial Taurus, 2009.

Solís, Manuel. Costa Rica la democracia de las razones débiles (y los pasajes ocultos). San José: Instituto de Investigaciones Sociales. Editorial Universidad de Costa Rica, 2018.

Torres, Edelberto. «Las crisis de las democracias en América Latina». Revista Instituto Interamericano de Derechos Humanos (IIDH), n. ${ }^{\circ} 42$ (2005): 211225.

Tuesta, Fernando. «Sistemas electorales en América Latina». Revista Instituto Interamericano de Derechos Humanos (IIDH), n. $^{\circ} 42$ (2005): 145-160.

Urdánoz, Jorge. «Un nuevo marco conceptual para el análisis electoral». Tesis doctoral. Universidad de La Rioja, 2005.

Várnagy, Tomas. «El pensamiento político de John Locke y el surgimiento del liberalismo». En La filosofía política moderna. De Hobbes a Marx, compilado por Atilio Boron, 41-76. Buenos Aires: Consejo Latinoamericano de Ciencias Sociales (CLACSO), 2000.

Wallerstein, Immanuel. Universalismo europeo. Ciudad de México: Siglo Veintiuno Editores, 2007.

Weber, Max. Economía y Sociedad. Ciudad de México: Fondo de Cultura Económica, 1969.

Zavaleta, René. «Cuatro conceptos de democracia». En: La autodeterminación de las masas, compilado por Luis Tapia, 121-143. Bogotá: Siglo del Hombre Editores y Consejo Latinoamericano de Ciencias Sociales (CLACSO), 2009. 